\title{
Power loss reduction by arctic wolf optimization algorithm
}

\author{
Kanagasabai Lenin \\ Department of EEE, Prasad V. Potluri Siddhartha Institute of Technology, India
}

\begin{tabular}{l} 
Article Info \\
\hline Article history: \\
Received Jul 19, 2019 \\
Revised Nov 12, 2019 \\
Accepted Nov 27, 2019 \\
\hline
\end{tabular}

\section{Keywords:}

Arctic wolf optimization Optimal reactive power Transmission loss

\begin{abstract}
This paper proposes Arctic Wolf optimization (AWO) algorithm to solve the optimal reactive power problem. Deeds of the Arctic wolf have been imitated to formulate the proposed algorithm. Arctic wolf also identified as the white wolf or polar wolf is a breed of gray wolf inhabitant from Melville Island to Ellesmere Island. It is average size, very smaller when compared to north western wolf, it possess whiter coloration, narrower braincase and big carnassials. Particle swarm optimization, Genetic algorithm has been used to improve the Exploration \& Exploitation ability of the algorithm by utilizes flag vector \& position, velocity update properties. Proposed Arctic Wolf optimization (AWO) algorithm has been tested in standard IEEE 30 bus test system and simulation results show the projected algorithms reduced the real power loss considerably.
\end{abstract}

Copyright (C) 2019 Institute of Advanced Engineering and Science. All rights reserved.

\section{Corresponding Author:}

Kanagasabai Lenin, Department of EEE, Prasad V. Potluri Siddhartha Institute of Technology, Chalasani Nagar, Kanuru, Vijayawada, Andhra Pradesh 520007, India.

Email: gklenin@gmail.com

\section{INTRODUCTION}

Reactive power problem plays an important role in secure and economic operations of power system. Numerous types of methods [1-6] have been utilized to solve the optimal reactive power problem. However many scientific difficulties are found while solving problem due to an assortment of constraints. Evolutionary techniques [7-16] are applied to solve the reactive power problem. This paper proposes Arctic Wolf optimization (AWO) algorithm to solve the optimal reactive power problem. Arctic wolf also identified as the white wolf or polar wolf is a breed of gray wolf inhabitant from Melville Island to Ellesmere Island. It is average size, very smaller when compared to north western wolf, it possess whiter coloration, narrower braincase and big carnassials. Arctic wolf is fairly unafraid of people, and can be entice to approach people in several areas. Very particularly they do not fear humans \& approach cautiously, curiously and closely. During wintertime when there is absolute darkness Arctic wolf will make the movement at temperature was as low as $-53^{\circ} \mathrm{C}\left(-63^{\circ} \mathrm{F}\right)$ and mainly they prey mainly on the muskoxen. Muskoxen are certainly their most important prey because Arctic wolf presence and reproduction seem to be superior when muskoxen are more available than normal availability. Particle swarm optimization, Genetic algorithm has been used to improve the Exploration \& Exploitation ability of the algorithm by utilizes flag vector \& position, velocity update properties. Proposed Arctic Wolf optimization (AWO) algorithm has been tested in standard IEEE 57 bus test system and simulation results show the projected algorithm reduced the real power loss considerably.

\section{PROBLEM FORMULATION}

Objective of the problem is to reduce the true power loss:

$$
\mathrm{F}=\mathrm{P}_{\mathrm{L}}=\sum_{\mathrm{k} \in \mathrm{Nbr}} \mathrm{g}_{\mathrm{k}}\left(\mathrm{V}_{\mathrm{i}}^{2}+\mathrm{V}_{\mathrm{j}}^{2}-2 \mathrm{~V}_{\mathrm{i}} \mathrm{V}_{\mathrm{j}} \cos \theta_{\mathrm{ij}}\right)
$$


voltage deviation given as follows:

$$
\mathrm{F}=\mathrm{P}_{\mathrm{L}}+\omega_{\mathrm{v}} \times \text { Voltage Deviation }
$$

voltage deviation given by:

$$
\text { Voltage Deviation }=\sum_{\mathrm{i}=1}^{\mathrm{Npq}}\left|\mathrm{V}_{\mathrm{i}}-1\right|
$$

constraint (Equality)

$$
\mathrm{P}_{\mathrm{G}}=\mathrm{P}_{\mathrm{D}}+\mathrm{P}_{\mathrm{L}}
$$

constraints (Inequality)

$$
\begin{aligned}
& \mathrm{P}_{\mathrm{gslack}}^{\min } \leq \mathrm{P}_{\mathrm{gslack}} \leq \mathrm{P}_{\mathrm{gslack}}^{\max } \\
& \mathrm{Q}_{\mathrm{gi}}^{\min } \leq \mathrm{Q}_{\mathrm{gi}} \leq \mathrm{Q}_{\mathrm{gi}}^{\max }, \mathrm{i} \in \mathrm{N}_{\mathrm{g}} \\
& \mathrm{V}_{\mathrm{i}}^{\min } \leq \mathrm{V}_{\mathrm{i}} \leq \mathrm{V}_{\mathrm{i}}^{\max }, \mathrm{i} \in \mathrm{N} \\
& \mathrm{T}_{\mathrm{i}}^{\min } \leq \mathrm{T}_{\mathrm{i}} \leq \mathrm{T}_{\mathrm{i}}^{\max }, \mathrm{i} \in \mathrm{N}_{\mathrm{T}} \\
& \mathrm{Q}_{\mathrm{c}}^{\min } \leq \mathrm{Q}_{\mathrm{c}} \leq \mathrm{Q}_{\mathrm{C}}^{\max }, \mathrm{i} \in \mathrm{N}_{\mathrm{C}}
\end{aligned}
$$

\section{ARCTIC WOLF OPTIMIZATION}

Arctic Wolf optimization (AWO) mimics the deeds of Arctic Wolf in nature. The deeds of the arctic wolf have been imitated to formulate the algorithm. During wintertime when there is absolute darkness Arctic wolf will make the movement at temperature was as low as $-53^{\circ} \mathrm{C}\left(-63^{\circ} \mathrm{F}\right)$ and mainly they prey mainly on the muskoxen. Muskoxen are certainly their most important prey because Arctic wolf presence and reproduction seem to be superior when muskoxen are more available than normal availability. Hunting procedure of the arctic wolf is designed to formulate the algorithm. There are three fittest candidate solutions (Arctic Wolf) embedded as $\alpha, \beta$ and $\gamma$ to lead the population toward capable regions of the exploration space in each iteration of Arctic Wolf optimization. $\varphi$ is named for the rest of Arctic Wolf and it will assist $\alpha, \beta$ and $\gamma$ to encircle, hunt, and attack prey; to find improved solutions. In order to technically imitate the encircling deeds of Arctic wolves, the following equations are projected:

$$
\begin{aligned}
& \vec{H}=\left|\vec{I} \cdot \overrightarrow{J_{P}}(t)-\vec{J}(t)\right|, \\
& \vec{J}(t+1)=\overrightarrow{J_{P}}(t)-\vec{J} \cdot \vec{H}
\end{aligned}
$$

in order to scientifically imitate the hunting deeds of Arctic wolf, the following equations are projected,

$$
\begin{aligned}
& \overrightarrow{H_{\alpha}}=\left|\overrightarrow{I_{1}}, \overrightarrow{J_{\alpha}}-\vec{J}\right| \\
& \overrightarrow{H_{\beta}}=\left|\overrightarrow{I_{2}}, \overrightarrow{J_{\beta}}-\vec{J}\right| \\
& \overrightarrow{H_{\gamma}}=\left|\overrightarrow{I_{3}}, \overrightarrow{J_{\gamma}}-\vec{J}\right| \\
& \overrightarrow{J_{1}}=\overrightarrow{J_{\alpha}}-\overrightarrow{G_{1}} \cdot \overrightarrow{H_{\alpha}} \\
& \overrightarrow{J_{2}}=\overrightarrow{J_{\beta}}-\overrightarrow{J_{2}} \cdot \overrightarrow{H_{\beta}} \\
& \overrightarrow{J_{3}}=\overrightarrow{J_{\gamma}}-\overrightarrow{G_{3}} \cdot \overrightarrow{H_{\gamma}} \\
& \vec{J}(t+1)=\frac{\overrightarrow{J_{1}}+\overrightarrow{J_{2}}+\overrightarrow{J_{3}}}{3}
\end{aligned}
$$

The position of an Arctic wolf is modernized and then the following equation is used to discrete the position of the wolf; 


$$
\text { flag }_{i, j}=\left\{\begin{array}{cc}
1 & J_{i, j}>0.475 \\
0 & \text { otherwise }
\end{array}\right.
$$

where $\mathrm{i}$, indicates the $\mathrm{jth}$ position of the ith Arctic wolf, $\operatorname{flag}_{i, j}$ is features of the Arctic wolf. The interactions of the Arctic wolf among them is increased by,

$$
\omega_{i}^{d}=j_{i}^{d}+\varphi_{i d}\left(j_{\alpha}^{d}-z_{i}^{d}\right)+\varphi_{i d}\left(j_{j}^{d}-j_{k}^{d}\right)
$$

The confined density of the Arctic wolf is denoted by,

$$
\rho_{i}=\sum_{j \in T /\{i\}} e^{-\left(\frac{d_{i j}}{d c}\right)^{2}}
$$

Arctic wolf is less than " $d c$ " when the the Arctic wolf's distance from the $\mathrm{j}_{i}$, the greater than the confined density of the Arctic wolf. $d_{i j}$ symbolize the Euclidean distance between the $\mathrm{j}_{i}, \mathrm{j}_{j}$ of Arctic wolf, $\varphi_{\mathrm{id}}$ is a arbitrary number in $[0,1], \varphi_{\text {id }}$ is a arbitrary number in $[-1,1]$

"2 m" Arctic Wolf with the leading confined thickness is chosen \& well-organized by density [17] from big to little in set "R". Afterwards, " 2 m" Arctic Wolf"s, are selected to adjust to the most awful Arctic Wolf's and it has been placed in set "Y" with reference to the fitness values from very small to large. " $\mathrm{X}$ " and "Y" intersection of sets is symbolized by " $E$ ":

$$
\begin{aligned}
& E=X \cap Y \\
& E=\left\{e ; e_{i} \in S, e_{i} \in X, i=1,2, \ldots, i\right\}
\end{aligned}
$$

Two major abolition methods are implemented. Let "V" be the store to stockpile the abolished individuals,

$$
V=\left\{\begin{array}{c}
V_{1}, \text { random }>e^{\left(\frac{t}{t_{\text {maximum }}}\right)^{2}} \\
S[1 ; E], \text { other }
\end{array}\right.
$$

Arbitrary numbers are engendered by the random function in the interval $[0,1]$. The probability of the establishment of random $>e^{\left(\frac{t}{t_{\text {maximum }}}\right)^{2}}$ in the primary stage is big. With the increase in iteration steps, the probability will be reducing to lesser. The algorithm to be inclined to explore globally, and afterwards, the algorithm is apt to explore local mode.

Positions and velocities are modernized to improve the performance of the exploration \& exploitation in the projected algorithm.

$$
\begin{aligned}
& v_{t+1}^{i}=\omega_{t} \cdot v_{t}^{i}+c g_{1} \cdot R m_{1} \cdot\left(m_{t}^{i}-y_{t}^{i}\right)+c g_{2} \cdot R m_{2} \cdot\left(m_{t}^{g}-y_{t}^{i}\right) \\
& y_{t+1}^{i}=y_{t}^{i}+v_{t+1}^{i}
\end{aligned}
$$

The present position of particle is $\mathrm{y}_{\mathrm{t}}^{\mathrm{i}}$ \& search velocity is $\mathrm{v}_{\mathrm{t}}^{\mathrm{i}}$. Global best-found position is. $\mathrm{m}_{\mathrm{t}}^{\mathrm{g}}$. In uniformly distributed interval $(0,1) \mathrm{Rm}_{1} \& \mathrm{Rm}_{2}$ are arbitrary numbers. Where $\mathrm{cg}_{1}$ and $\mathrm{cg}_{2}$ are scaling parameters. $\omega_{\mathrm{t}}$ is the particle inertia. The variable $\omega_{\mathrm{t}}$ is modernized as:

$$
\omega_{t}=\left(\omega_{\max }-\omega_{\min }\right) \cdot \frac{\left(t_{\max }-t\right)}{t_{\max }}+\omega_{\min }
$$

Maximum and minimum of $\omega_{t}$ is represented by $\omega_{\max }$ and $\omega_{\min }$; maximum number of iterations is given by $t_{\max }$.

Genetic algorithm (GA) as an adaptive optimization exploration method is based on natural selection and genetics. In GA, a population is composed of a set of candidate solutions called chromosomes and it includes numerous genes with binary values 0 and 1.The major steps are of GA are. (i) Initialization; Chromosomes are arbitrarily generated. (ii) Selection; to choose parent chromosomes a roulette choosing method is used. (iii) Crossover; to generate offspring chromosome a single point crossover method is used. (iv) Mutation; unvarying mutation is implemented (v) Decode; Decode the mutated chromosomes as the preliminary positions of population. 
Fitness function will be calculated by,

$$
\text { Fitness }=\alpha T+\beta \frac{M-G}{M}
$$

Where $\mathrm{T}$ define the accurateness, $\mathrm{G}$ is the length of chosen element division, $\mathrm{M}$ is the sum of all features, and $\alpha$ and $\beta$ are the weight of classification and picking quality, $\alpha \in[0,1]$ and $\beta=1-\alpha$

Initialization of the parameters

$\mathrm{i}=1$ : population size; $\mathrm{j}=1: \mathrm{n}$

When $(i, j)>0.475$; $(i)=1$; Else $(j)=0$;

End if

End for

Calculation of the fitness functions by; Fitness $=\alpha T+\beta \frac{M-G}{M}$

Primary, secondary, third maximum fitness of the Arctic wolf is designated as " $\alpha$ ", " $\beta$ ", " $\gamma$ "

While $\mathrm{k}<$ maximum number of iteration

For $\mathrm{i}=1$ : population size

Modernize the existing position of Arctic wolf by $\vec{J}(t+1)=\frac{\overrightarrow{J_{1}}+\overrightarrow{J_{2}}+\overrightarrow{J_{3}}}{3}$

Existing wolf Arctic location has been revised periodically

End for

For $\mathrm{i}=1$ : population size; For $\mathrm{i}=1: \mathrm{n}$

If $(i, j)>0.475 ;(j)=1$; Else; $(j)=0$;

End if

End for

At irregular intervals renew the parameter values

Fitness function will be calculated by; Fitness $=\alpha T+\beta \frac{M-G}{M}$

The assessment of Arctic Wolf " $\alpha$ "," $\beta$ " and " $\gamma$ " has to be revised

$\mathrm{t}=\mathrm{t}+1$;

End while

Return the best solution" $\alpha$ “

End

\section{SIMULATION STUDY}

Proposed Arctic Wolf optimization (AWO) algorithm has been tested, in IEEE 57 Bus system [18]. Table 1 shows the constraints of control variables, Table 2 shows the limits of reactive power generators and comparison results are presented in Table 3. Figure 1 gives the Comparison of real power loss and Figure 2 gives the Reduction of real power loss (\%) with reference to base case value.

Table 1. Constraints of control variables

\begin{tabular}{cccc}
\hline System & Variables & Minimum (PU) & Maximum (PU) \\
\hline IEEE & Generator Voltage & 0.95 & 1.1 \\
57 Bus & Transformer Tap & 0.9 & 1.1 \\
& VAR Source & 0 & 0.20 \\
\hline
\end{tabular}

Table 2. Constrains of reactive power generators

\begin{tabular}{cccc}
\hline System & Variables & Q Minimum $(\mathrm{PU})$ & Q Maximum $(\mathrm{PU})$ \\
\hline IEEE 57 Bus & 1 & -140 & 200 \\
& 2 & -17 & 50 \\
& 3 & -10 & 60 \\
& 6 & -8 & 25 \\
& 8 & -140 & 200 \\
& 9 & -3 & 9 \\
& 12 & -150 & 155 \\
\hline
\end{tabular}


Table 3. Simulation results of IEEE-57 system

\begin{tabular}{|c|c|c|c|c|c|c|}
\hline Control variables & Base case & MPSO [19] & PSO [19] & CGA [19] & AGA [19] & AWO \\
\hline$V G 1$ & 1.040 & 1.093 & 1.083 & 0.968 & 1.027 & 1.008 \\
\hline$V G 2$ & 1.010 & 1.086 & 1.071 & 1.049 & 1.011 & 1.012 \\
\hline$V G 3$ & 0.985 & 1.056 & 1.055 & 1.056 & 1.033 & 1.004 \\
\hline$V G 6$ & 0.980 & 1.038 & 1.036 & 0.987 & 1.001 & 1.029 \\
\hline$V G 8$ & 1.005 & 1.066 & 1.059 & 1.022 & 1.051 & 1.048 \\
\hline$V G 9$ & 0.980 & 1.054 & 1.048 & 0.991 & 1.051 & 1.039 \\
\hline$V G 12$ & 1.015 & 1.054 & 1.046 & 1.004 & 1.057 & 1.026 \\
\hline Tap 19 & 0.970 & 0.975 & 0.987 & 0.920 & 1.030 & 0.911 \\
\hline Tap 20 & 0.978 & 0.982 & 0.983 & 0.920 & 1.020 & 0.909 \\
\hline Tap 31 & 1.043 & 0.975 & 0.981 & 0.970 & 1.060 & 0.906 \\
\hline Tap 35 & 1.000 & 1.025 & 1.003 & $\mathrm{NR}^{*}$ & $\mathrm{NR}^{*}$ & 1.007 \\
\hline Tap 36 & 1.000 & 1.002 & 0.985 & $\mathrm{NR}^{*}$ & $\mathrm{NR}^{*}$ & 1.021 \\
\hline Tap 37 & 1.043 & 1.007 & 1.009 & 0.900 & 0.990 & 1.032 \\
\hline Tap 41 & 0.967 & 0.994 & 1.007 & 0.910 & 1.100 & 0.947 \\
\hline Tap 46 & 0.975 & 1.013 & 1.018 & 1.100 & 0.980 & 1.028 \\
\hline Tap 54 & 0.955 & 0.988 & 0.986 & 0.940 & 1.010 & 0.939 \\
\hline Tap 58 & 0.955 & 0.979 & 0.992 & 0.950 & 1.080 & 0.928 \\
\hline Tap 59 & 0.900 & 0.983 & 0.990 & 1.030 & 0.940 & 0.938 \\
\hline Tap 65 & 0.930 & 1.015 & 0.997 & 1.090 & 0.950 & 1.026 \\
\hline Tap 66 & 0.895 & 0.975 & 0.984 & 0.900 & 1.050 & 0.939 \\
\hline Tap 71 & 0.958 & 1.020 & 0.990 & 0.900 & 0.950 & 1.042 \\
\hline Tap 73 & 0.958 & 1.001 & 0.988 & 1.000 & 1.010 & 1.012 \\
\hline Tap 76 & 0.980 & 0.979 & 0.980 & 0.960 & 0.940 & 0.906 \\
\hline Tap 80 & 0.940 & 1.002 & 1.017 & 1.000 & 1.000 & 1.030 \\
\hline$Q C 18$ & 0.1 & 0.179 & 0.131 & 0.084 & 0.016 & 0.140 \\
\hline$Q C 25$ & 0.059 & 0.176 & 0.144 & 0.008 & 0.015 & 0.131 \\
\hline$Q C 53$ & 0.063 & 0.141 & 0.162 & 0.053 & 0.038 & 0.120 \\
\hline$P G(\mathrm{MW})$ & 1278.6 & 1274.4 & 1274.8 & 1276 & 1275 & 1272.67 \\
\hline$Q G$ (Mvar) & 321.08 & 272.27 & 276.58 & 309.1 & 304.4 & 272.38 \\
\hline $\begin{array}{l}\text { Reduction in } \\
\text { PLoss }(\%)\end{array}$ & 0 & 15.4 & 14.1 & 9.2 & 11.6 & 27.43 \\
\hline Total PLoss (Mw) & 27.8 & 23.51 & 23.86 & 25.24 & 24.56 & 20.172 \\
\hline
\end{tabular}

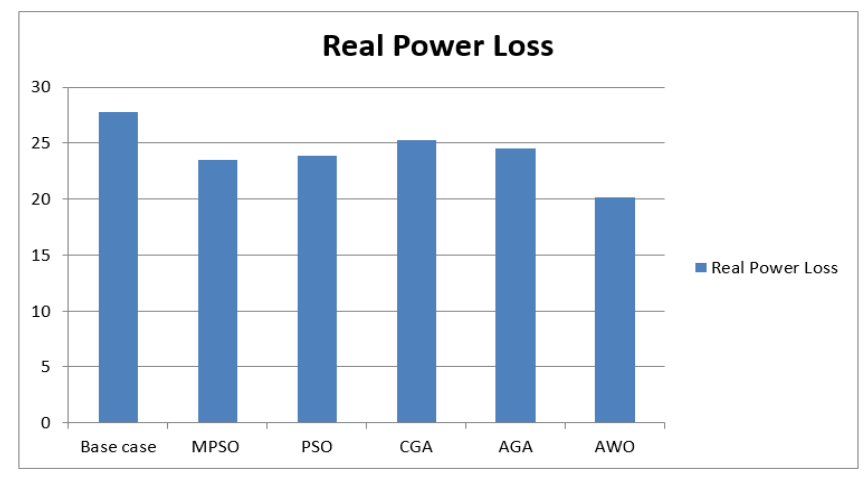

Figure 1. Comparison of real power loss

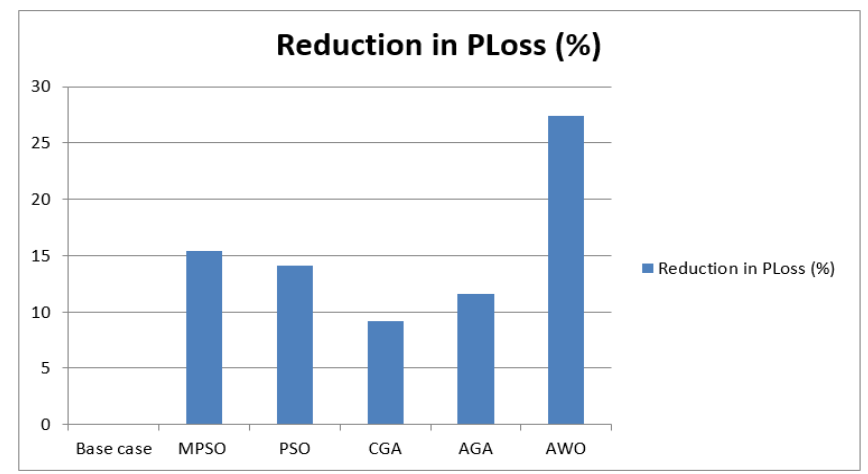

Figure 2. Reduction of real power loss (\%) with reference to base case value 


\section{CONCLUSION}

In this paper Arctic Wolf optimization (AWO) algorithm successfully solved the optimal reactive power problem. (Arctic Wolf) embedded as $\alpha, \beta$ and $\gamma$ to lead the population toward capable regions of the exploration space in each iteration of Arctic Wolf optimization. $\varphi$ is named for the rest of Arctic Wolf and it will assist $\alpha, \beta$ and $\gamma$ to encircle, hunt, and attack prey. .Proposed Arctic Wolf optimization (AWO) algorithm has been tested in standard IEEE 57 bus test system and simulation results show the projected algorithms reduced the real power loss efficiently.

\section{REFERENCES}

[1] K. Y. Lee, "Fuel-cost minimisation for both real and reactive-power dispatches," Proceedings Generation, Transmission and Distribution Conference, vol. 131(3), pp. 85-93, 1984.

[2] N. I. Deeb, "An efficient technique for reactive power dispatch using a revised linear programming approach," Electric Power System Research, vol. 15(2), pp. 121-134, 1998.

[3] M. R. Bjelogrlic, M. S. Calovic, B. S. Babic, "Application of newton's optimal power flow in voltage/reactive power control," IEEE Trans Power System, vol. 5(4), pp. 1447-1454, 1990.

[4] S. Granville, "Optimal reactive dispatch through interior point methods," IEEE Transactions on Power System, vol. 9(1), pp. 136-146, 1994.

[5] N. Grudinin, "Reactive power optimization using successive quadratic programming method," IEEE Transactions on Power System, vol. 13(4), pp. 1219-1225, 1998.

[6] Ng Shin Mei R., Sulaiman M.H., Mustaffa Z., Daniyal H., "Optimal reactive power dispatch solution by loss minimization using moth-flame optimization technique," Appl. Soft Comput., vol. 59, pp. 210-222, 2017.

[7] Chen G., Liu L., Zhang Z., Huang S., "Optimal reactive power dispatch by improved GSA-based algorithm with the novel strategies to handle constraints," Appl. Soft Comput., vol. 50, pp. 58-70, 2017.

[8] Naderi E., Narimani H., Fathi M., Narimani M. R., "A novel fuzzy adaptive configuration of particle swarm optimization to solve large-scale optimal reactive power dispatch," Appl. Soft Comput., vol. 53, pp. 441-456, 2017.

[9] Heidari A. A., Ali Abbaspour R., Rezaee Jordehi A., "A gaussian bare-bones water cycle algorithm for optimal reactive power dispatch in electrical power systems," Appl. Soft Comput., vol. 57, pp. 657-671, 2017.

[10] Mahaletchumi Morgan, Nor Rul Hasma Abdullah, Mohd Herwan Sulaiman, Mahfuzah Mustafa, Rosdiyana Samad, "Benchmark studies on optimal reactive power dispatch (ORPD) based multi-objective evolutionary programming (MOEP) using mutation based on adaptive mutation adapter (AMO) and polynomial mutation operator (PMO)," Journal of Electrical Systems, vol. 12(1), 2016.

[11] Rebecca Ng Shin Mei, Mohd Herwan Sulaiman, Zuriani Mustaffa,"Ant lion optimizer for optimal reactive power dispatch solution," Journal of Electrical Systems, pp. 68-74, 2016.

[12] P. Anbarasan, T. Jayabarathi, "Optimal reactive power dispatch problem solved by symbiotic organism search algorithm," Innovations in Power and Advanced Computing Technologies, 2017.

[13] Gagliano A., Nocera F., "Analysis of the performances of electric energy storage in residential applications," International Journal of Heat and Technology, vol. 35(1), pp. S41-S48, 2017.

[14] Caldera M., Ungaro P., Cammarata G., Puglisi G., "Survey-based analysis of the electrical energy demand in Italian households," Mathematical Modelling of Engineering Problems, vol. 5(3), pp. 217-224, 2018.

[15] M. Basu, "Quasi-oppositional differential evolution for optimal reactive power dispatch," Electrical Power and Energy Systems, vol. 78, pp. 29-40, 2016.

[16] X. S. Yang, "Bat algorithm for multi-objective optimization," International Journal of Bio-Inspired Computation, vol. 3(5), pp. 267-274, 2011.

[17] Y. W. Yamany, E. Emary and A. E. Hassanien, "Wolf search algorithm for attribute reduction in classification," Computational Intelligence and Data Mining (CIDM), 2014 IEEE Symposium, IEEE, pp. 351-358, 2014.

[18] IEEE, "The IEEE-test systems," 1993. http://www.ee.washington.edu/trsearch/pstca/

[19] Ali Nasser Hussain, Ali Abdulabbas Abdullah and Omar Muhammed Neda, "Modified particle swarm optimization for solution of reactive power dispatch," Research Journal of Applied Sciences, Engineering and Technology, vol. 15(8), pp. 316-327, 2018. 